\begin{tabular}{|c|c|c|c|}
\hline & $\begin{array}{l}\text { FATTiH } \\
\text { SULTAN } \\
\text { MEHMET } \\
\text { VAKIF ÜNivERSTIESS }\end{array}$ & $\begin{array}{l}\text { FSM İlmî Araştırmalar Insan ve Toplum Bilimleri Dergisi } \\
\text { FSM Scholarly Studies Journal of Humanities and Social Sciences } \\
\text { Sayı/Number } 17 \text { Yıl/Year } 2021 \text { Bahar/Spring } \\
\text { (c) } 2021 \text { Fatih Sultan Mehmet Vakıf Üniversitesi }\end{array}$ & 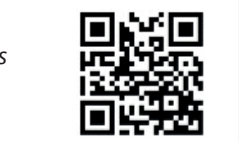 \\
\hline DOI: & & http://dergipark.org.tr/fsmia & http://dergi.fsm.edu.tr \\
\hline Yayın $\mathrm{L}$ & lirme / Book Reviews & Geliş Tarihi / Received: 11.03.2021 Kabul Tarihi / Accepted: 19.06.2021 & FSMIAD, 2021; (17): 825-832 \\
\hline
\end{tabular}

\title{
Stephen J. Lee, Avrupa Tarihinden Kesitler 1494-1789, çev. Ertürk Demirel,
}

Ankara: Dost Kitabevi, 2019, 9789752980174, 295 s.

Muazzez Gündüz Oğul*

Stephen J. Lee, Avrupa Tarihi üzerine yapmış olduğu çalışmalarla bilinmektedir. Yazarın kaleminden çıkan Avrupa Tarihinden Kesitler 1494-1789 adlı kitapta, söz konusu dönem aralığında Avrupa Tarihi'nde öne çıkan olaylar dizisi incelenmiştir. Stephen J. Lee'nin Avrupa Tarihinden Kesitler 1789-1980 adl1 bir çalışması daha bulunmakta ve bu kitap, çalışma kapsamında değerlendirilen eserin devamı niteliğindedir. İncelenen kitapta Modern Avrupa Tarihi'nin erken döneminde yaşanan olaylar kısa ve öz nitelikte toplamda otuz altı bölümde, kronolojik olarak ele alınmıştır. Her bölümün ana teması kendi içerisinde özeldir. $\mathrm{Bu}$ anlamda kitabın kendisi bir yapboza benzetilebilir ve bölümler de yapbozun parçaları olarak düşünülebilir.

Kitap İngilizce olarak 1978 y1lında kaleme alınmış, Türkçeye ise 2002 yılında, Ertürk Demirel tarafından çevrilmiştir. Çalışma kapsamında kitabın yedinci baskısı değerlendirilmiştir. Çeviri kitaplarda okurlar için en önemli husus öncelikle sahih olmasıdır. Bu açıdan değerlendirildiğinde çevirmenin Avrupa Tarihi'ne konu olan siyasi ve sosyal olayları ustalıkla okuyucuya sunması göz ardı edilemez bir başarı olarak yorumlanabilir. Çünkü dönemin kavram ve terimleri ile birlikte düşünüldüğünde olayların ve gelişmelerin oldukça anlaşılır bir şekilde ele alındığı görülmektedir.

* Arş. Gör., Sinop Üniversitesi Fen-Edebiyat Fakültesi Tarih Bölümü, Sinop/Türkiye, mgunduz@sinop.edu.tr, orcid.org/0000-0001-8369-7912 
Stephen J. Lee kitaba takdim niteliğinde kısa bir giriş ile başlamıştır. Özellikle eserinde, Avrupa Tarihi'nin erken dönemine konu olan olayları yorumlayıc1 bir biçimde ele aldığını dile getirmiştir. Ayrıca eserinin Avrupa Tarihi dersleri için temel bir başvuru kaynağı iddiası taşımadığını, bunun yerine yardımcı kaynak niteliğinde kaleme alındığını ifade etmiş̧tir. Bu bakımdan Stephen J. Lee'nin kitabı yazmasındaki temel amacı okuyucuya yorumlayıcı ve sorgulayıcı bir yön katmak ve karmaşık ilişkiler ağı olarak görülen Avrupa Tarihi'ni tüm yönleriyle, özet bir biçimde okuyucuya sunmak olarak yorumlanabilir ${ }^{1}$.

Stephen J. Lee kitapta ilk olarak Rönesans ve hümanizm konularını ele almıştır. Bu anlamda Rönesans'1, Tanrı merkezli bir evren anlayışından insan merkezli bir evren anlayışına geçiş olarak ifade etmiştir. Eserde Rönesans düşünce yapısının mimariden sanat anlayışına, yaşamın her noktasında hissedildiği özellikle vurgulanmıştır. Orta çağ mimarisini Gotik, sivri ve karamsar yapılar oluştururken, Rönesans mimarisini daha alçak, yuvarlak yapılar oluşturmaktadır. Rönesans’ta insana yaklaşmak ve onu tüm yönleriyle anlamak öne çıkmaktadır. Eserde Rönesans ile birlikte hümanist düşünce anlayışına dikkat çekilmiştir. Burada hümanist düşünce, insanın ön plana çıkması ve çalışmanın önem kazanması olarak ifade edilmiştir.

Yazar Rönesans hareketi ve hümanist düşünce yapısının doğurduğu siyasi ortamı ayrı bölümlerde fakat birbirinin ardılı olarak incelemiştir. Özellikle Rönesans düşünce yapısının siyasi ortama etkisi üzerinde dururken, bu dönemde devletlerin de kiliseden bağımsız olarak hareket etmek istediğinin altını çizmiştir. Avrupa'da daha önce Kutsal Roma Germen İmparatorluğu'na bağlı devletler varken artık söz konusu devletler, papadan ve Vatikan'dan bağımsız hareket etmek istemişlerdir. İnsanı ve evreni gerçek yönleri ile anlamanın öne çıktığı söz konusu dönemde reformasyon kaçınılmaz olmuştur. Stephen J. Lee reformasyonu, sömürü düzeni kuran kiliseye karşı oluşan belirgin hoşnutsuzluğun bir ifadesi olarak yorumlarken, 16. yüzyıl başlarında papa karşıtı duyguların zirveye ulaşması şeklinde de ifade etmiştir. Bu kapsamda ulusal kiliselerin ortaya çıkışı söz konusudur. Çünkü matbaanın keşfi ile basılan ve bölge lehçelerine çevrilen İncil, birçok yere ulaşabilir hale gelmiş ve kiliseye karşı duyulan güven sarsılmıştır.

Entelektüel eleştirilerin ortaya çıkması ve düşüncelerin Avrupa'ya yayılmas1 kuşkusuz reform hareketini etkilemiştir. Yaşanan tüm gelişmeler çerçevesinde yazar, 16. yüzyıl başlarında Luther'in ve onun fikirlerinin ayakta kalabilmesinin

1 Konunun kapsam olarak geniş, bölümlerinin ise sayıca fazla olması sebebiyle incelemede bölüm-konu ayrımından ziyade ele alınan olayların içeriklerine bağlı kalınarak genel ve bütüncül bir değerlendirme yapılmaya çalışmıştır. 
ve yayılmasının en önemli nedenini Orta Avrupa'daki siyasi durumda görmüştür. Çünkü bu dönemde Papa'nın ve imparator I. Maximilanus'un taht ile ilgili siyasal çıkarları vardır ve onlar bu çıkarlar çerçevesinde hareket etmişlerdir. Papa bu dönemde Haçlı Seferleri organize etmek istemiştir ve bu nedenle Luther'in hareket sahasına müdahale edememiştir. Zira Lutherciliğin en fazla yayıldığı yer Almanya'dır ve papalığın en önemli gelir kaynağını Almanya'dan gelen vergiler oluşturmaktadır. Haçlı Seferi organize etmek isteyen papanın karşısında aynı dönemde Osmanlı Devleti tahtında Kanuni Sultan Süleyman bulunmaktadır. Yazarın tüm bu olayları belirli bir sıra ve ilişki içerisinde ele alması kitabın anlaşılabilirliğini arttırmıştır. Avrupa tarihine yön veren Luther'in bu kapsamda incelenmesi ve Kutsal Roma Germen İmparatorluğu'nun durumu şüphesiz birbirinden ayrı olarak ele alınamazd.

Düşünce dünyası ile siyasi yapı üzerinde gerçekleşen değişim birbirinden bağımsız düşünülemeyeceğinden yazar daha önce de ifade edildiği gibi tüm bu gelişmeleri neden-sonuç ilişkisi içinde harmanlamıştır. Avrupa tarihinin en karmaşık yönü siyasi yapısıdır. Özellikle Kutsal Roma İmparatorluğu bunun bir örneğidir. Yazar bu konuda kafa karışıklığını gideren bir anlatımla hem Luther'in durumunu hem de imparatorluğun karmaşık yapısını etraflı ve anlaşılır bir biçimde farklı bölümlerde incelemiştir. Özellikle Maximilianus'un 1519'daki ölümünden sonra tahta I. Karl'ın çıkması ve papanın dikkatini ancak bundan sonra Luther'e verebilmesi yazar tarafından önemle ele alınmıştır. Luther ilk olarak aforoz edilerek kanun kaçağı sayılmıştır. I. Karl, 1516'da İspanya tahtına çıkarken 1519 'da V. Karl unvaniyla Kutsal Roma Germen İmparatoru olmuştur. Bu durum İspanya idaresini ciddi bir şekilde etkilemiştir. Çünkü söz konusu siyasi durumda Karl birden fazla unvana sahip olmuş ve İspanya'nın merkezi otoritesi olumsuz yönde bu durumdan etkilenmiştir. Birden fazla unvana sahip olan Karl, kırk yıllık yönetimi boyunca yalnızca on altı yıl İspanya'da bulunmuştur. İspanya'yı bu anlamda ihmal etmiş ve burayı konsiller aracıllğı ile yönetmiştir.

Stephen J. Lee söz konusu dönemi ele alırken Avrupa devletleri ile birlikte, özellikle Orta Avrupa tarihine yön veren Osmanlı İmparatorluğu'nu da farklı bölümlerde özel olarak incelemiştir. İmparatorluğun Avrupa ve Asya'daki en güçlü dönemini Muhteşem (Kanuni Sultan) Süleyman çağında yaşadığını belirten yazar, Türklerin sonrasında Viyana'yı alamasalar da hiçbir Hristiyan ordusunu İstanbul'a 300 milden daha fazla yaklaştırmadıklarını da ayrıca eklemiştir.

Olayları kronolojik olarak ele alan yazar 1494'ten 1559'a kadar süren İtalyan savaşlarını iki ana bölüme ayırarak incelemiştir. Bu anlamda 1494-1516 yılları arasında İtalya'ya karşı açılan savaşlar yaşanırken 1522-1559 arası dönemde ise 
Habsburg-Valois Mücadelesi ile Fransa ve Avusturya-İspanya mücadelesi ortaya çıkmıştır. Bu esnada Kutsal Roma Germen İmparatorluğu 1493-1618 arası dönemde kurumsal zayıflıklar, dinsel çatışmalar ve Bohemya'daki durumdan dolayı sürekli olarak güç kaybı yaşamıştır. Bohemya'da Protestanlık temelli bir isyan çıkmış ve bu durum çatışma ortamına neden olmuştur.

Arka arkaya yaşanan İtalyan Savaşları ve 30 Yıl Savaşları'nın Kutsal Roma Germen İmparatorluğu'nu daha da kötü etkilemiştir. Yazar eserinde tüm siyasi gelişmeleri incelerken, olayları özellikle devletlerin çıkarları çerçevesinde ele almıştır. Stephen J. Lee, "30 Yıl Savaşları" teriminin yaşanan savaşlardan ve Vestfalya Antlaşması'ndan yirmi yıl sonra ortaya çıktığını öne sürmüş, savaşlara katılan devletleri ise İtalya hariç Fransa, Danimarka, İsveç ve Avusturya-İspanya Habsburgları olarak sıralamıştır. Savaşlar temelde, Katolik ve Protestan çatışmas1 üzerine yükselen ve siyasal birliğini korumak isteyen Kutsal Roma Germen İmparatorluğu ile bağımsızlıklarını sağlamak isteyen tâbi devletler arasındaki anlaşmazlıkları ifade etmektedir. Kutsal Roma Germen İmparatorluğu bu dönemde daha önce ifade edilen sebeplerden dolayı oldukça zayıf durumda kalmıştır. Fransa ve İsveç ise imparatorluğun güçsüz durumundan yararlanmak istemiştir. Yaşanan savaşlardan sonra 1648'de Habsburg elçileri ile Münster'de, İsveç ile de Osnabück'te Vestfalya Antlaşması imzalanmıştır. İsveç, Fransa kadar güçlü olduğu için ayrı antlaşma imzalamıştır. Yazara göre anlaşma, Avrupa Devletleri'nin 150 yılı boyunca, siyasal gelişmelerinde ve dinsel yapılarında belirleyici rol oynamıştır.

İçeriği ile birlikte değerlendirildiğinde yazar, Vestfalya Antlaşması'nı düzen sağlayıcı bir antlaşma olarak belirtmiştir. Çünkü bu antlaşma yöneticileri, dinsel farklılıklara hoşgörü ile bakmalarına teşvik etmiş, devletin resmi dinini prenslerin seçimine bırakmıştır. Bu anlamda sadece prenslere din seçme hakkı tanıyan Augsburg Antlaşması'nın sebep olduğu yanlışların Vestfalya Antlaşması ile telafi edildiği söylenebilir.

Yaşanan siyasi gelişmelerin ardından Stephen J. Lee, İspanyol ve Portekiz imparatorluklarının gelişimi ile ilgili tarihsel perspektifle bilgiler vermiştir. Konuya sömürgecilik faaliyetleri ile giriş yapan yazar, Afrika, Asya ve Amerika'da sömürgeler kurulmasına yönelik ilk hareketlerin 15. ve 16. yüzyıllarda önemli keşifler gerçekleştirilen İber Yarımadası'nda doğduğunu ifade etmiştir. Bu anlamda Portekiz ilk olarak 1415 yılı itibariyle denizlerdeki keşiflerine başlamış, İspanya ise buna sonradan dâhil olmuştur.

Portekizlilerin sömürge alanlarını Afrika kıyıları ve Hint Okyanusu kıyıları olarak ifade eden yazar, İspanya sömürgelerini ise Kanarya adaları, Bat1 Hint 
adalarının çoğu ve Orta Amerika'nın tamamı, Güney Amerika'nın önemli bir bölümü, Filipinler olarak sıralamıştır. Bu iki imparatorluğun keşif hareketlerini karşılaştırdığında ise Portekizlilerin keşiflerini daha dikkatli ve sistematik yaptıklarının altını çizmiştir.

Yazar siyasi olarak dönemin olaylarını ele alırken, imparatorlukların talihini belirleyen, tarihe yön vermiş kişileri de belirli açılardan ele almıştır. XIV. Louis'nin yönetim anlayışını işleyen yazar, kendisinin mutlak monarşiyi yüzde yüze yakın hale getirdiğini ifade etmiştir. Onun döneminde kralın kişisel itibarıyla hanedan ve ulusun itibarı ayrılmaz bir bütün olarak görülmüş, kendisinden önce Richelieu tarafından inşa edilen yapı, Louis ile sağlamlaştırılmıştır. Voltaire onu "kendini çalışmaya adamış kişi”" olarak betimlemiştir.

XIV. Louis'nin ardından Büyük Elektör olarak bilinen Friedrich Wilhelm'1 ve dönemini inceleyen yazar, kendisinin kurumsal yapı adına gerçekleştirdiği güçlü reformları ile Prusya'nın temellerini attı̆̆ının altını çizmiştir. Özellikle Büyük Friedrich'in yarı özerk bölgelerden oluşan siyasi yapıyı merkezileştirmeye çalıştığı bu noktada önemlidir.

Büyük Petro’yu ise reformcu bir kişi olarak tanımlayan Stephen J. Lee, onu Rusya'da geleneği reddeden ve uygarlık biçimini kökten bir şekilde değiştirmeyi amaçlayan kişi olarak görmüştür. Petro, askeri alanda yoğunlaştırdığ1 reformları ile askerliği zorunlu hale getirmiş ve ateşli silahların yaygınlaştırılması ile askeri eğitime önem vermiştir. Yazar aynı zamanda I. Petro'nun Rusya'da ilk deniz filosunu ve ulusal ordusunu oluşturduğunun altını çizmiş̧ir. Ona göre Petro'nun askeri alandaki reformları başarılı iken idari alanda yapmak istediklerini Büyük Yekaterina (1762-1796) hayata geçirmiştir.

Petro'nun otoriter yönü üzerinde sıklıkla duran yazar, sanayide devletleştirme yanlısı olduğunu ve yabancıların elinde bulunan, sınırlı sayıdaki sanayi kuruluşlarını devletleştirdiğini ifade etmiştir. Bu durum ise yeni üretim alanlarının doğmasını sağlamıştır. Kendisi aynı zamanda askeri ihtiyaçları karşılamaya yönelik alanlara yönelmiştir. Örnek olarak demir, ağır sanayi ve dokuma (üniforma, yelken bezleri) alanları verilebilir. Büyük Petro döneminde Rusya, büyük bir devlet statüsüne sahip olmuştur.

Rusya'da Büyük Yekaterina döneminin geniş kapsamlı reformlarla başladığını ifade eden yazar, yaşanan gelişmelerin tutucu bir anlayışın güçlenmesiyle bittiğini ifade etmiştir. Büyük Yekaterina ilk başta aydınlanma felsefesinden esinlendiği düşüncelerini uygulamaya koymayı çalışsa da sonrasında sadece mevcut koşulları korunmaya çalışmıştır. Yazar, Büyük Yekaterina'nın Almanya'da geçen gençliği boyunca, Aydınlanma felsefesi ile yakından ilgilendiğini 
ve antik ve çağdaş filozofların eserlerine karşı yoğun ilgisini sürdürdüğünü dile getirirken bu anlamda Montesquieu, Voltaire, Diderot, d'Alembert ve Ansiklopediciler gibi Aydınlanma felsefesinin önemli temsilcileriyle düzenli olarak yazıştığının altını çizmiştir. Büyük Yekaterina, Batı ile olan entelektüel bağlarını korumuştur. İlk başta felsefeye duyduğu ilgi öne çıkarken sonrasında resim, tiyatro, müzik ve mimari ile ilgili kültürel boyuttaki çalışmaları ile dikkat çekmiştir.

Rusya'nın 18. yüzyılda dış siyasetini inceleyen yazar, Büyük Petro'nun hakimiyeti tamamen ele geçirdiği 1689 ile Büyük Yekaterina'nın öldüğü 1796 yılı arasındaki dönemde üç önemli evre görmüştür. Buna göre ilk evre (1689-1725) Büyük Petro'nun tahta çıkışıyla ölümü arasındaki süreç içinde tamamlanmış ve Rusya büyük devlet statüsüne sahip bir güç olarak ortaya çıkmıştır. İkinci evrede (1725-1762) Rusya, Avrupa diplomasisinde giderek etkili olmaya başlamıştır. Aslında bu dönem Batı ile yeni ilişkilerin gelişimi adına bir deneme süreci olarak da ifade edilebilir. Son evrede ise Rusya diplomatik sahada öne çıkmış, savaş meydanında kazandığı başarılar ile fetih hareketlerini hızlandırmıştır.

Eserin devamında Maria Theresa döneminde Avusturya'yı değerlendiren yazar, Maria Theresa'nın yeniliklere açık olduğunu ifade etmiştir. Özellikle kendisinin bu anlamda eskimiş ve artık dönemin koşullarına cevap veremeyen merkezi ve bölgesel kurumları değiştirmeyi amaçlaması dikkat çekicidir. Maria Theresa'nın dönemi boyunca gerçekleştirdiği değişiklikleri üç bölümde toplayan Stephen J. Lee bunları kurumsal-hukuksal, iktisadi-toplumsal ve dinsel değişikler olarak incelemiştir. Maria Theresa'nın acil olarak gerçekleştirmek istediği şeyin Macaristan ve Belçika'yı birleştirecek yeni kurumlar inşa etmekten ziyade, Avusturya-Bohemya topraklarında otoritesini sağlamlaştırmak olduğuna dikkat çekmiştir. Kendisinden sonra yönetime geçen II. Joseph'in bir dizi radikal değişim gerçekleştirildiğini ifade eden yazar, II. Joseph'in yönetimi süresince, "Benim emirlerimin ve ilkelerimin takip edilmesinde ve istisnasiz uygulanmalarında ısrarlıyım" sözlerinde onun yönetimine dair ipuçlarının bulunabileceğini ifade etmiştir. Çünkü II. Joseph, aydınlanmaya ancak mutlak otorite yardımıyla ulaşılabileceğine inanmıştır.

Akıl Çağı'nı, inanç çağı ve ideolojiler çağı olarak da tanımlayan yazar, bu dönemin 17. yüzyılın ikinci yarısından 18. yüzyılın sonuna kadar geçen süreyi kapsadığını ileri sürmüştür. Bunu ise inançların değiştirilmeye zorlanmadığı bir dönem olarak tanımlamıştır. Aydınlanma Çağı'nda yeni mantığın ayrılmaz bir parçası olan aklın kutsallığını ve yüceliğini savunan filozoflar söz konusuyken, artık insan doğasının mükemmel olmadığı yazar tarafından dile getirilmiştir. 
Akıl Çağı'nın, 18. yüzyıldan itibaren ilerlemeye devam ettiğini belirten Stephen L. Jee, bunun 18. yüzyılın ikinci yarısının başlarında en güçlü zamanını yaşadığını ifade etmiştir. Sonrasında ise filozofların insan aklını mükemmellikten uzak ve sadece bazı davranışların gerçekleştirilebilmesine imkân sağlayan bir araç olarak görmeye başlamalarıyla, dönemin bittiğinin altını çizmiştir.

Yazarın 18. yüzyılda Akıl Çă̆ı'nın, Aydınlanma hareketi süresince en güçlü dönemini yaşadığını ve bu konuda merkezin Fransa olduğunu ifade etmiştir. Fransa içinde ise Aydınlanma felsefesi, salonlarda tartışmayı seven asiller sayesinde yayılmıştır.

Aydınlanmış despotizme eserde yer veren yazar, 18. yüzyılda Avrupa'nın belirli bölgelerinde uygulanan mutlakıyet yönetimleri ile Alman ve Fransız Aydınlanma filozoflarının fikirleri arasındaki bağlantıyı ifade etmiştir. Aydınlanma felsefesinin sağladığı yöntemler ve içeriğin yanı sıra, yöneticilerin kendilerini haklı çıkarmak için de bu düşünce akımını kullandıklarını vurgulamıştır. Yöneticiler, filozofların bazı fikirlerinden esinlenerek, öncelikli sorunlarını ve amaçlarını belirlemekte daha mantıklı yaklaşımlar izlemişlerdir. Yazar aydınlanmış despotlara örnek olarak Büyük Friedrich (1740-86), Büyük Yekaterina (1762-1796) ve II. Joseph (1780-90)'i vermiştir. Çünkü onlar hem Fransız hem de Alman filozoflar ile sıkı bağlara sahip olmuşlar ve bu şekilde öne çıkmışladır.

Fransa'da XV. Louis'nin yönetimini inceleyen Stephen J. Lee, onun 1743'e kadar yönetimde tek başına söz sahibi olamadığını, öncesinde Fransa'nın, Orleans'ın naipliği tarafindan (1715-23) ve daha sonra Louis'nin yavaş yavaş kral rolüne soyunduğu dönem boyunca da Kardinal Fleury (1726-43) tarafindan yönetildiğini ifade etmiştir. Kardinal Fleury, resmi olarak başbakan sıfatını taşımasa da kendisi görülmemiş bir boyutta yönetimde yetkiye sahip olmuştur. Yazar aydınlanmış despotların ülkeleri ile karşıllaştırıldığında, XV. Louis ve XVI. Louis dönemleri boyunca Fransa'nın önemli reformlardan mahrum kaldığının sık sık ifade edildiğini fakat bunun çok da gerçeği yansıtmadığını özellikle belirtmiştir. Çünkü 1743 'te Kardinal Fleury'den yönetimi devralan XV. Louis, reformlara karş1 tam bir duruş sergileyememiş ve köklü planlar geliştirememiştir. Aslında onun içinde bulunduğu koşullar reformları zorunlu hale getirmiştir. Bu süreçte savaşların artan mali baskısı ile yardımcılarının birçoğu, Fleury’nin değişikliklerinden daha geniş etkilere sahip olacak 1slahatlar gerçekleştirme gerekliliğini hissetmişlerdir. XVI. Louis'nin tahta çıkışından (1774) sonra, reform hareketleri giderek kötüleşen ekonomi ve Aydınlanma felsefesinin doğurduğu yeni fikirlerin sonucu olarak hız kazanmıştır. 
XIV. Louis'nin bir kopyası olarak XV. Louis'yi ele alan yazar, onun devlet işleriyle ilgilenmediğini ve Voltaire'in Büyük Friedrich için yaptığı yakıştırma ile kendisini "makamıyla alakasız" bir yönetici olarak ün saldığını belirtmiştir. Genel olarak değerlendirdiğinde 18. yüzyıl süresince Fransa'nın askeri gücünün ve diplomatik prestijinin doruklarına, ilk olarak XVI. Louis'nin ve sonra da I. Napoleon'un başta oldukları dönemlerde ulaştığını ifade eden yazar, bu iki yönetim arasında Fransız dış siyasetini, aktif fakat büyük ölçüde başarısız olarak yorumlamıştır.

Kitap İngilizce olarak 1978 yılında kaleme alınmış, Türkçeye ise 2002 yılında, Ertürk Demirel tarafından çevrilmiştir. Çalışma kapsamında kitabın yedinci baskısı değerlendirilmiştir. Çeviri kitaplarda okurlar için en önemli husus öncelikle sahih olmasıdır. Bu açıdan değerlendirildiğinde çevirmenin Avrupa Tarihi'ne konu olan siyasi ve sosyal olayları ustalıkla okuyucuya sunması göz ardı edilemez bir başarı olarak yorumlanabilir. Çünkü dönemin kavram ve terimleri ile birlikte düşünüldüğünde olayların ve gelişmelerin oldukça anlaşılır bir şekilde ele alındığı görülmektedir.

Birçok kitaba konu olan Avrupa Tarihi, şüphesiz önemli ancak anlaşılması bir o kadar da güç bir alandır. Avrupa Tarihi ile ilgili yapılan çalışmalarda çoğunlukla tek bir konu üzerinden, derinlemesine inceleme yapılırken Rönesans'tan hümanizme, Kutsal Roma Germen İmparatorluğu'ndan aydınlanmış despotizme kadar karışık ilişkiler ağını oluşturan olaylar, Stephen J. Lee tarafından tarihsel çizgide, bütüncül bir yaklaşımla ele almıştır. İnsanın ön plana çıktı̆̆ı dönem itibari ile Rönesans ve Reform hareketlerinin incelenmesi, yaşanan gelişmelerin siyasi yapıya etkileri, önde gelen liderlerin dış siyaset anlayışları ve akıl çağının nasıl gelişim gösterdiği ile ilgili birçok konu kitapta, neden-sonuç ilişkisi içerisinde incelenmiştir. Bu anlamda bölümlerin ana temalarına bağlı kalınarak, gelişmelerin kısa ve akıcı bir dille işlenmesi önemlidir. Konunun anlaşılmasını kolaylaştıran bu husus, kitabı okuyucu için özel kılmakta ve alanın daha da derinden incelenmesine teşvik etmektedir. 